\title{
Sequence Analysis of the UCP1 Gene in a Severe Obese Population from Southern Italy
}

\author{
Giuseppe Labruna, ${ }^{1}$ Fabrizio Pasanisi, ${ }^{2}$ Giuliana Fortunato, ${ }^{3,4}$ Carmela Nardelli, ${ }^{3,4}$ \\ Carmine Finelli, ${ }^{5}$ Eduardo Farinaro, ${ }^{6}$ Franco Contaldo, ${ }^{2}$ and Lucia Sacchetti ${ }^{3,4}$ \\ ${ }^{1}$ Fondazione IRCCS SDN, Istituto di Ricerca Diagnostica e Nucleare, Via Gianturco 113, 80143 Naples, Italy \\ ${ }^{2}$ Centro Interuniversitario di Studi e Ricerche sull'Obesità e Dipartimento di Medicina Clinica e Sperimentale, \\ Università degli Studi di Napoli Federico II, Via Pansini 5, 80131 Naples, Italy \\ ${ }^{3}$ CEINGE Biotecnologie Avanzate S.C. a R.L., Via Gaetano Salvatore 486, 80145, Naples, Italy \\ ${ }^{4}$ Dipartimento di Biochimica e Biotecnologie Mediche, Università degli Studi di Napoli Federico II, \\ Via Pansini 5, Via Pansini 5, 80131 Naples, Italy \\ ${ }^{5}$ Fondazione Stella Maris Mediterraneo, Centro Disturbi del Comportamento Alimentare e del Peso "G. Gioia”, \\ Chiaromonte, C/da S. Lucia, 85100, Chiaromonte, Potenza, Italy \\ ${ }^{6}$ Dipartimento di Scienze Mediche Preventive, Università degli Studi di Napoli Federico II, Via Pansini 5, 80131 Naples, Italy
}

Correspondence should be addressed to Lucia Sacchetti, sacchett@unina.it

Received 1 December 2010; Accepted 8 April 2011

Academic Editor: Francesco Saverio Papadia

Copyright (C) 2011 Giuseppe Labruna et al. This is an open access article distributed under the Creative Commons Attribution License, which permits unrestricted use, distribution, and reproduction in any medium, provided the original work is properly cited.

\begin{abstract}
Brown adipose tissue, where Uncoupling Protein 1 (UCP1) activity uncouples mitochondrial respiration, is an important site of facultative energy expenditure. This tissue may normally function to prevent obesity. Our aim was to investigate by sequence analysis the presence of UCP1 gene variations that may be associated with obesity. We studied 100 severe obese adults (BMI $>40 \mathrm{~kg} / \mathrm{m}^{2}$ ) and 100 normal-weight control subjects $\left(\right.$ BMI range $=19-24.9 \mathrm{~kg} / \mathrm{m}^{2}$ ). We identified 7 variations in the promoter region, 4 in the intronic region and 4 in the exonic region. Globally, 72\% of obese patients bore UCP1 polymorphisms. Among UCP1 variants, g.IVS4-208T >G SNP was associated with obesity (OR: 1.77; 95\% CI =1.26-2.50; $P=.001$ ). Further, obese patients bearing the g. $-451 \mathrm{C}>\mathrm{T}(\mathrm{CT}+\mathrm{TT})$ or the g.940G $>$ A $(\mathrm{GA}+\mathrm{AA})$ genotypes showed a higher BMI than not polymorphic obese patients $(P=.008$ and $P=.043$, resp.). In conclusion, UCP1 SNPs could represent "thrifty" factors that promote energy storage in prone subjects.
\end{abstract}

\section{Introduction}

Brown adipose tissue (BAT) plays an important role in energy expenditure [1]. Its thermogenic activity requires not only the presence of a dense vascularisation and sympathetic innervation, but also the expression of Uncoupling Protein 1 (UCP1) $[2,3]$. UCP1 is localized on the inner mitochondrial membrane where it uncouples oxidative metabolism from ATP synthesis, resulting in the dissipation of energy through the release of heat [4]. In humans, BAT exerts its function especially during the first years of life and decreases with age [5]. However, several metabolic active depots of BAT have been recently demonstrated also in adult humans [6-8]. It has been calculated that BAT malfunction could lead to a weight gain of $1-2 \mathrm{~kg} / \mathrm{yr}$ [9]. These data suggest that BAT specific proteins, such as UCP1, could be involved in obesity onset so representing a possible target of pharmaceutical interventions in this field $[10,11]$. In the last years, $U C P 1$ loss has been associated with obesity susceptibility in $U C P 1^{-/-}$ mice, particularly during aging and a high-fat diet [12, 13]. We previously described the association between the variation $-3826 \mathrm{~A}>\mathrm{G}$ in the $U C P 1$ promoter and a severe fatty liver steatosis during obesity [14]. The aim of this study was to search for further gene alterations associated with obese phenotype in the UCP1 gene (ENSG00000109424) by sequence analysis. 
TABLe 1: General and biochemical characteristics of obese patients and control subjects.

\begin{tabular}{lcc}
\hline & $\begin{array}{c}\text { Obese patients } \\
(n=100)\end{array}$ & $\begin{array}{c}\text { Control subjects } \\
(n=100)\end{array}$ \\
\hline Females $(\%)$ & 60 & 64 \\
Age $($ years $)$ & $32.1 \pm 10.9$ & $33.3 \pm 8.1$ \\
BMI* $\left(\mathrm{kg} / \mathrm{m}^{2}\right)$ & $47.9 \pm 6.9$ & $22.8 \pm 2.1$ \\
Adiponectin* $(\mu \mathrm{g} / \mathrm{mL})$ & $31.6 \pm 30.0$ & $53.8 \pm 38.6$ \\
Leptin* $(\mathrm{ng} / \mathrm{mL})$ & $119.6 \pm 72.4$ & $21.9 \pm 18.7$ \\
Resistin $(\mathrm{ng} / \mathrm{mL})$ & $12.2 \pm 8.4$ & $12.7 \pm 7.9$ \\
Glucose* $(\mathrm{mmol} / \mathrm{L})$ & $4.9 \pm 0.8$ & $4.5 \pm 0.4$ \\
Total cholesterol $(\mathrm{mmol} / \mathrm{L})$ & $4.7 \pm 1.1$ & $5.0 \pm 0.7$ \\
Triacylglycerols* $(\mathrm{mmol} / \mathrm{L})$ & $1.5 \pm 0.6$ & $0.9 \pm 0.3$ \\
AST* $(\mathrm{U} / \mathrm{L})$ & $26.5 \pm 16.7$ & $19.8 \pm 5.6$ \\
ALT* $(\mathrm{U} / \mathrm{L})$ & $39.8 \pm 35.0$ & $22.5 \pm 12.9$ \\
GGT* $(\mathrm{U} / \mathrm{L})$ & $35.3 \pm 26.0$ & $17.4 \pm 10.4$ \\
Creatinine $(\mathrm{mg} / \mathrm{dL})$ & $0.9 \pm 0.2$ & $0.7 \pm 0.1$ \\
\hline
\end{tabular}

${ }^{*}$ Statistically significant difference between obese and control subjects, $P<$ .001 at Mann-Whitney test. Biochemical parameters were measured by routine laboratory methods. Adipokines concentrations were measured by ELISA assay (LINCO Research, Mo, USA). Values are expressed as mean \pm SD.

\section{Materials and Methods}

We studied 200 age-matched unrelated Caucasian subjects from Southern Italy: 100 adult severe obese patients $(60 \%$ female, mean $\pm \mathrm{SD}: \mathrm{BMI}=47.9 \pm 6.9 \mathrm{~kg} / \mathrm{m}^{2}$; age $=$ $32.1 \pm 10.9$ years $)$ and 100 unrelated adult normal-weight subjects $\left(64 \%\right.$ female, mean $\pm \mathrm{SD}: \mathrm{BMI}=22.8 \pm 2.1 \mathrm{~kg} / \mathrm{m}^{2}$; age $=33.3 \pm 8.1$ years $)$. The patients were recruited at the obesity outpatient clinic of the Department of Clinical and Experimental Medicine, University of Naples Federico II, Italy, from 2007 to 2008, whereas control subjects were recruited at the Department of Preventive Medical Science of the Federico II University Hospital. Clinical and biochemical data were obtained from each patient on their first admission. The general and biochemical characteristics of the studied populations are reported in Table 1. All patients and controls gave their informed consent to the study, which was carried out according to the Helsinki II Declaration. The research was also approved by the Ethics Committee of the School of Medicine, University of Naples Federico II.

Genomic DNA was extracted from whole blood (Nucleon BACC-II; Amersham Science Europe). UCP1 5' flanking region, exons and intron-exon junction regions were amplified by ten sets of primers (primers ID: RSA000984680, RSA000984677, RSA000984675, RSA000984673, RSA00098 4666, RSA000990288, RSA000990284, RSA000990283, RSA0 00990281, and RSA000990278 http://www.ncbi.nlm.nih.gov/ sites/entrez). PCR products were sequenced on ABI Prism 3130 Genetic Analyzer (Applied Biosystems, Foster City, CA). PCR conditions were $96^{\circ} \mathrm{C}$ for $5 \mathrm{~min}$; than $94^{\circ} \mathrm{C}$ for 30 sec, $60^{\circ} \mathrm{C}$ for $45 \mathrm{sec}$ and $72^{\circ} \mathrm{C}$ for $45 \mathrm{sec}$, for 40 cycles; final extension at $72^{\circ} \mathrm{C}$ for $10 \mathrm{~min}$; final soak at $25^{\circ} \mathrm{C}$.
The mean value and the standard deviation (SD) were calculated for each investigated parameter. The MannWhitney test and/or $\chi^{2}$, when necessary, were used for between-group comparisons. Differences were considered significant at $P$ level <.05. Linkage analysis was performed by using Haploview 4.0 software [15]. Binomial logistic regression analysis was used to investigate the association between the biochemical and genetic characteristics (i.e., glucose, total cholesterol and triacylglycerols concentrations and AST activity; g. $-451 \mathrm{C}>\mathrm{T}$, g.940G >A, g.IVS4-208, and g.6537A $>\mathrm{T}$ polymorphisms) and the condition of being obese, after adjustment for age and sex.

Statistical analyses were carried out with the PASW package for Windows (Ver.18; SPSS Inc. Headquarters, Chicago, Ill).

\section{Results and Discussion}

Adiponectin and leptin concentrations were statistically different $(P<.001)$ between obese and control subjects (mean level \pm SD respectively: adiponectin $31.6 \pm 30.0 \mu \mathrm{g} / \mathrm{mL}$ versus $53.8 \pm 38.6 \mu \mathrm{g} / \mathrm{mL}$; leptin $119.6 \pm 72.4$ versus $21.9 \pm$ $18.7 \mathrm{ng} / \mathrm{mL}$ ). Higher concentrations or activities of glucose, triacylglycerols, AST, ALT and GGT were measured in obese patients than in controls $(P<.001)$ (Table 1$)$.

We identified 15 sequence variations in UCP1 gene (Table 2$): 7$ in the promoter region (3/7 described for the first time), 4 in the intronic regions ( $1 / 4$ described for the first time) and 4 in the exonic regions ( 2 in the $5^{\prime}$ UTR; 2 in the translated region). Globally, $72 \%$ of obese patients bore one or more UCP1 polymorphisms.

There were no differences in genotype frequencies between obese and control subjects at level of the detected SNPs, except for g.IVS4-208T $>$ G polymorphism more frequent in obese than in control subjects $(P=.002)$. After a permutation test with 100000 permutations, the association of the polymorphic allele with the obese phenotype remained statistically significant $(P=.017)$. Subjects bearing this polymorphism (TG or GG) were at high risk for obesity (OR: $1.774 ; 95 \% \mathrm{CI}=1.26-2.50, P=.001)$. At binomial logistic regression analysis, the g.IVS4-208 (TG+GG) genotype was confirmed to be statistically associated in our patients with obesity independently of sex and age (OR: 22.0; 95\% $\mathrm{CI}=5.6-87.1)$. This SNP did not alter the splicing site nor the branch site [16, http://www.umd.be/HSF/], and the polymorphic allele did not change the $\Delta G$ of the predicted mRNA secondary structure by mfold analysis (http://mfold.bioinfo.rpi.edu), suggesting that the stability of the polymorphic mRNA is the same as the wild-type. The $G$ allele may be a marker linked to other gene variants promoting energy storage as well as fat accumulation in prone subjects.

The novel UCP1 variants g. $-637 \mathrm{~T}>\mathrm{C}$, g. $-206 \mathrm{C}>\mathrm{A}$, and g.IVS2 $+174 \mathrm{~T}>\mathrm{A}$, each of them present in a single obese patient, were not associated with differences in clinical and/or biochemical parameters measured in the obese and control populations. Among them, only the g. $-206 \mathrm{C}>\mathrm{A}$ occurred in a conserved region indentified by cisRED algorithm (http://www.cisred.org/) as a cis-regulatory element 
TABLE 2: UCP1 sequence variations and their frequencies in obese and control subjects.

\begin{tabular}{|c|c|c|c|c|c|c|c|}
\hline \multicolumn{2}{|c|}{ Polymorphisms } & \multicolumn{3}{|c|}{$\begin{array}{l}\text { Obese patients } \\
\quad n=100\end{array}$} & \multicolumn{3}{|c|}{$\begin{array}{l}\text { Control subjects } \\
\qquad n=100\end{array}$} \\
\hline Position & rs\# & wt & $\mathrm{HE}$ & $\mathrm{HO}$ & wt & $\mathrm{HE}$ & $\mathrm{HO}$ \\
\hline g. $-637 \mathrm{~T}>\mathrm{C}^{1}$ & & 99 & 1 & 0 & 100 & 0 & 0 \\
\hline g. $-451 \mathrm{C}>\mathrm{T}$ & rs 36207410 & 82 & 16 & 2 & 86 & 14 & 0 \\
\hline g. $-412 \mathrm{~A}>\mathrm{C}$ & rs3811787 & 57 & 36 & 7 & 49 & 43 & 8 \\
\hline g. $-372 \mathrm{~A}>\mathrm{C}$ & rs1800660 & 97 & 3 & 0 & 97 & 3 & 0 \\
\hline g. $-206 \mathrm{C}>\mathrm{A}^{1}$ & & 99 & 1 & 0 & 100 & 0 & 0 \\
\hline g. $-56 \mathrm{C}>\mathrm{T}$ & rs3749539 & 91 & 9 & 0 & 90 & 10 & 0 \\
\hline g. $-17 C>G^{1}$ & & 94 & 6 & 0 & 94 & 6 & 0 \\
\hline g. $12 \mathrm{~A}>\mathrm{C}$ & rs 10011540 & 91 & 9 & 0 & 90 & 10 & 0 \\
\hline g. $21 \mathrm{G}>\mathrm{A}$ & rs1800661 & 86 & 13 & 1 & 79 & 21 & 0 \\
\hline g.940G >A (p.A64T) & rs45539933 & 92 & 8 & 0 & 91 & 9 & 0 \\
\hline g.IVS2+138C > T & rs7688743 & 80 & 15 & 5 & 70 & 27 & 3 \\
\hline g.IVS2+174T $>\mathrm{A}^{1}$ & & 99 & 1 & 0 & 100 & 0 & 0 \\
\hline g.IVS2+201T>G & rs2071416 & 79 & 21 & 0 & 77 & 22 & 1 \\
\hline g.IVS4-208T $>\mathrm{G}^{2}$ & rs1494808 & 45 & 44 & 11 & 69 & 23 & 8 \\
\hline g.6537A>T (p.M229L) & rs2270565 & 89 & 11 & 0 & 87 & 13 & 0 \\
\hline
\end{tabular}

${ }^{1}$ New variants; ${ }^{2}$ More frequent polymorphism in obese patients $(P=.002)$ than in controls. wt: wild-type homozygous subjects; HE: heterozygous and HO: homozygous subjects at level of the detected variant.

(craHsap157022), and we could hypothesize to alter the interaction with transcriptional factors.

Regarding the previously described UCP1 polymorphisms, a higher mean BMI was observed in our obese patients bearing the g. $-451 \mathrm{C}>\mathrm{T}(\mathrm{CT}+\mathrm{TT})$ than in not polymorphic obese patients (resp., $52.6 \pm 7.4 \mathrm{~kg} / \mathrm{m}^{2}$ versus $\left.47.0 \pm 6.6 \mathrm{~kg} / \mathrm{m}^{2}, P=.008\right)$.

The amino acidic substitution p.M229L (g.6537A>T) in the fifth helix of the protein is due to an $\mathrm{A}>\mathrm{T}$ transversion in the 5th exon of the UCP1 gene [17]. Mori and colleagues [18] found a higher frequency of the Leu allele of the p.M229L (g.6537A > T) polymorphism in a Japanese obese population with Type II diabetes, indicating this gene variation as a diabetes-associated SNP, while other studies failed to demonstrate such association $[9,19,20]$. In our study we found that patients carrying the polymorphic allele for the p.M229L polymorphism showed a slightly higher mean BMI than the wild-type patients $\left(50.6 \mathrm{~kg} / \mathrm{m}^{2}\right.$ versus $47.6 \mathrm{~kg} / \mathrm{m}^{2}$, resp.) while no difference were found at level of glucose and insulin concentration or regarding the homeostatic model assessment (HOMA) index (a measure of insulin sensitivity) (data not shown). This difference could be due to the lower mean age of our studied subjects (32.1 years in our patients versus 58.6 years in Mori et al. [18]), since Type II diabetes is more frequent in middle aged than in young adult patients.

Further, the haplotype investigation by Haploview software showed a significant linkage disequilibrium among the three SNPs g. $-56 \mathrm{C}>\mathrm{T}$ (a), g. $12 \mathrm{~A}>\mathrm{C}$ (b) and g. $940 \mathrm{G}>\mathrm{A}$ (c) (a-b: $\log$ likelihood ratio, $\mathrm{LOD}=27.5 ; r^{2}=1 ; \mathrm{b}-\mathrm{c}$ and ac: $\mathrm{LOD}=22.6 ; r^{2}=0.9$ ); however no statistically significant association was observed between obesity and this haplotype, the frequency of this latter being the same in obese and control subjects ( $8.0 \%$ versus $9.0 \%$, resp.).
The g.12A $>\mathrm{C}$ polymorphism is located in the insulin response sequence (IRS). In in vitro experiments, the DNA mutated $\mathrm{C}$ allele was demonstrated to reduce the transcription of UCP 1 by $40 \%$ respect to the wild-type allele. This variation was hypothesized to impair the affinity of the transcription factors for the consensus motif of IRS [18]. Further, this SNP was previously indicated as contributing to hepatic lipid accumulation and altering insulin sensitivity in Japanese individuals with Type II diabetes mellitus (NIDDM) [18]. In our population, the lack of association of this SNP with any obesity-related phenotype could be due to the younger mean age of our patients respect to those investigated by Fukuyama et al. [21] (32.1 years versus 56.6 years, resp.) and to different ethnic background of the studied groups.

The amino acidic substitution p.A64T (g.940G >A) in the first matrix loop of the protein is due to a $\mathrm{G}>\mathrm{A}$ transition in the 2nd exon of the UCP1 gene [17].

Cha et al. [22] reported in a Korean female population an association between the mutated allele and a higher blood pressure. In our population, polymorphic patients compared to wild-type patients showed a higher mean BMI (52.0 \pm $6.4 \mathrm{~kg} / \mathrm{m}^{2}$ versus $\left.47.5 \pm 6.9 \mathrm{~kg} / \mathrm{m}^{2}, P=.043\right)$ but only a trend toward a higher mean systolic blood pressure $(130.0 \mathrm{mmHg}$ versus $124.4 \mathrm{mmHg}$, resp.). This difference does not raise the statistically significant level probably due to the lower number of patients in our examined casistic.

\section{Conclusions}

Functional activity of BAT has been recently demonstrated in adult humans [6-8] and its amount is inversely related to body fat percentage [23]. We do not have any information 
in our patients about BAT amount. However, variations in the BAT marker UCP1 gene were present in most of our obese patients. These variations could represent common factors contributing to the development of obesity, particularly, g. $-451 \mathrm{C}>\mathrm{T}$, g.940G $>$ A, and g.IVS4-208T $>\mathrm{G}$ could represent "thrifty" factors that promote energy storage. The precise role in obesity of these variants should be investigated in a larger casistic.

\section{Acknowledgments}

The authors thank Jean Ann Gilder (Scientific Communication srl) for text revision and editing. The work supported by grants Conv. CEINGE-Regione Campania (DGRC 1901/2009), Regione Campania LR n5/2005 and MIUR PRIN 2008, and Progetto di Ricerca Finalizzata RF-SDN2007-635809 (Ministero del Lavoro, della Salute e delle Politiche Sociali).

\section{References}

[1] S. R. Farmer, "Molecular determinants of brown adipocyte formation and function," Genes and Development, vol. 22, no. 10, pp. 1269-1275, 2008.

[2] M. C. Zingaretti, F. Crosta, A. Vitali et al., "The presence of UCP1 demonstrates that metabolically active adipose tissue in the neck of adult humans truly represents brown adipose tissue," The FASEB Journal, vol. 23, no. 9, pp. 3113-3120, 2009.

[3] M. Rosenbaum and R. L. Leibel, "Adaptive thermogenesis in humans," International Journal of Obesity, vol. 34, pp. S47-S55, 2010.

[4] B. Cannon and J. Nedergaard, "Metabolic consequences of the presence or absence of the thermogenic capacity of brown adipose tissue in mice (and probably in humans)," International Journal of Obesity, vol. 34, pp. S7-S16, 2010.

[5] A. Frontini and S. Cinti, "Distribution and development of brown adipocytes in the murine and human adipose organ," Cell Metabolism, vol. 11, no. 4, pp. 253-256, 2010.

[6] S. Enerbäck, "Brown adipose tissue in humans," International Journal of Obesity, vol. 34, pp. S43-S46, 2010.

[7] K. A. Virtanen, M. E. Lidell, J. Orava et al., "Functional brown adipose tissue in healthy adults," The New England Journal of Medicine, vol. 360, no. 15, pp. 1518-1525, 2009.

[8] A. M. Cypess, S. Lehman, G. Williams et al., "Identification and importance of brown adipose tissue in adult humans," The New England Journal of Medicine, vol. 360, no. 15, pp. 15091517, 2009.

[9] S. A. Urhammer, M. Fridberg, T. I. Sørensen et al., "Studies of genetic variability of the uncoupling protein 1 gene in Caucasian subjects with juvenile-onset obesity," Journal of Clinical Endocrinology and Metabolism, vol. 82, no. 12, pp. 4069-4074, 1997.

[10] S. Costford, A. Gowing, and M. E. Harper, "Mitochondrial uncoupling as a target in the treatment of obesity," Current Opinion in Clinical Nutrition and Metabolic Care, vol. 10, no. 6, pp. 671-678, 2007.

[11] J. Nedergaard and B. Cannon, "The changed metabolic world with human brown adipose tissue: therapeutic visions," Cell Metabolism, vol. 11, no. 4, pp. 268-272, 2010.

[12] Y. Kontani, Y. Wang, K. Kimura et al., "UCP1 deficiency increases susceptibility to diet-induced obesity with age," Aging Cell, vol. 4, no. 3, pp. 147-155, 2005.
[13] H. M. Feldmann, V. Golozoubova, B. Cannon, and J. Nedergaard, "UCP1 ablation induces obesity and abolishes dietinduced thermogenesis in mice exempt from thermal stress by living at thermoneutrality," Cell Metabolism, vol. 9, no. 2, pp. 203-209, 2009.

[14] G. Labruna, F. Pasanisi, C. Nardelli et al., "UCP1 -3826 AG+GG genotypes, adiponectin, and leptin/adiponectin ratio in severe obesity," Journal of Endocrinological Investigation, vol. 32, no. 6, pp. 525-529, 2009.

[15] J. C. Barrett, B. Fry, J. Maller, and M. J. Daly, "Haploview: analysis and visualization of LD and haplotype maps," Bioinformatics, vol. 21, no. 2, pp. 263-265, 2005.

[16] F. O. Desmet, D. Hamroun, M. Lalande, G. Collod-Béroud, M. Claustres, and C. Béroud, "Human splicing finder: an online bioinformatics tool to predict splicing signals," Nucleic Acids Research, vol. 37, no. 9, article e67, 2009.

[17] J. Jiménez-Jiménez, R. Zardoya, A. Ledesma et al., "Evolutionarily distinct residues in the uncoupling protein UCP1 are essential for its characteristic basal proton conductance," Journal of Molecular Biology, vol. 359, no. 4, pp. 1010-1022, 2006.

[18] H. Mori, H. Okazawa, K. Iwamoto, E. Maeda, M. Hashiramoto, and M. Kasuga, "A polymorphism in the 5 ' untranslated region and a Met229-- > Leu variant in exon 5 of the human UCP1 gene are associated with susceptibility to type II diabetes mellitus," Diabetologia, vol. 44, no. 3, pp. 373-376, 2001.

[19] A. Hamann, J. Tafel, B. Büsing, H. Münzberg, A. Hinney, H. Mayer et al., "Analysis of the uncoupling protein-1 (UCP1) gene in obese and lean subjects: identification of four amino acid variants," International Journal of Obesity, vol. 22, no. 9, pp. 939-941, 1998.

[20] K. S. Vimaleswaran, V. Radha, R. Deepa, and V. Mohan, "Absence of association of metabolic syndrome with PPARGC1A, PPARG and UCP1 gene polymorphisms in Asian Indians," Metabolic Syndrome and Related Disorders, vol. 5, no. 2, pp. 153-162, 2007.

[21] K. Fukuyama, T. Ohara, Y. Hirota et al., "Association of the $112 \mathrm{~A}>\mathrm{C}$ polymorphism of the uncoupling protein 1 gene with insulin resistance in Japanese individuals with type 2 diabetes," Biochemical and Biophysical Research Communications, vol. 339, no. 4, pp. 1212-1216, 2006.

[22] M. H. Cha, B. K. Kang, D. Suh, K. S. Kim, Y. Yang, and Y. Yoon, "Association of UCP1 genetic polymorphisms with blood pressure among Korean female subjects," Journal of Korean Medical Science, vol. 23, no. 5, pp. 776-780, 2008.

[23] W. D. van Marken Lichtenbelt, J. W. Vanhommerig, N. M. Smulders et al., "Cold-activated brown adipose tissue in healthy men," The New England Journal of Medicine, vol. 360, no. 15, pp. 1500-1508, 2009. 


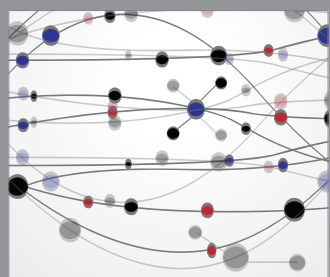

The Scientific World Journal
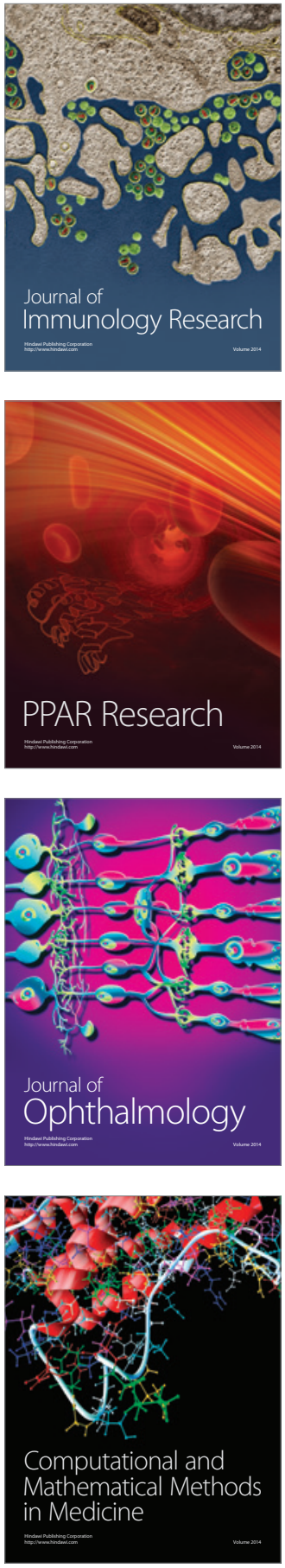

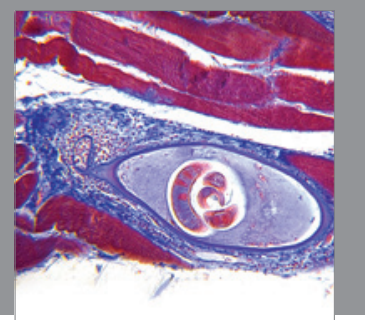

Gastroenterology

Research and Practice
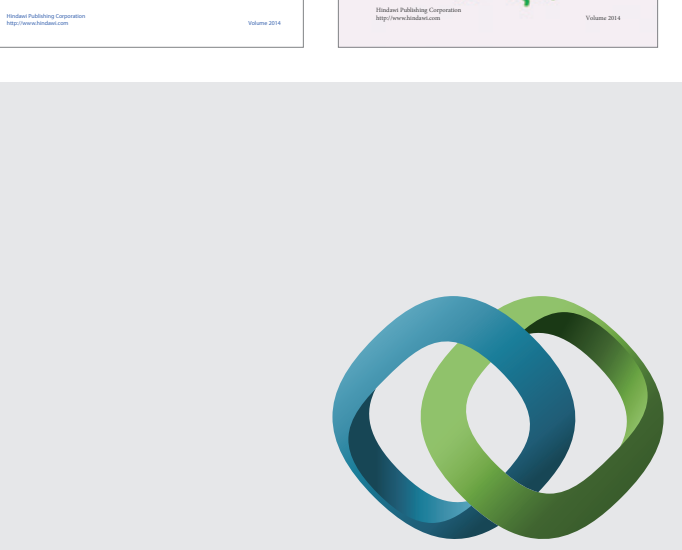

\section{Hindawi}

Submit your manuscripts at

http://www.hindawi.com
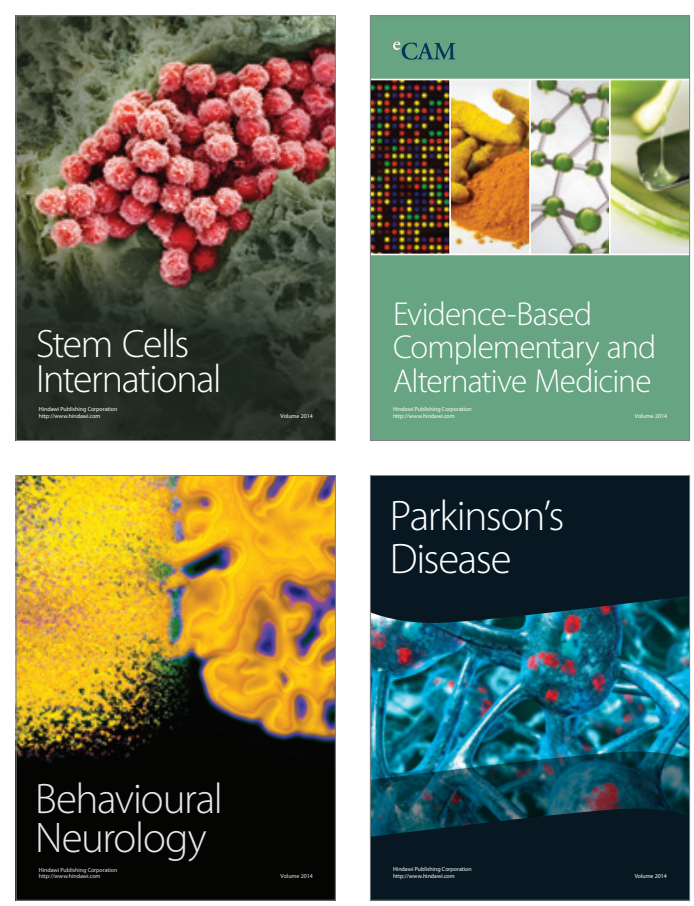

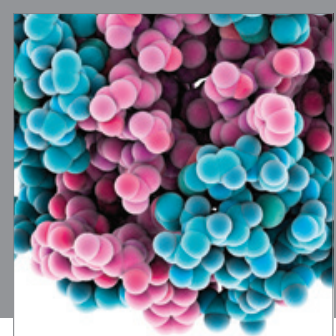

Journal of
Diabetes Research

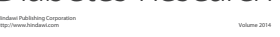

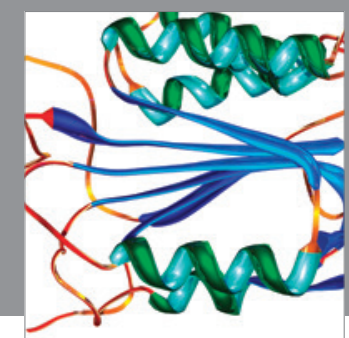

Disease Markers
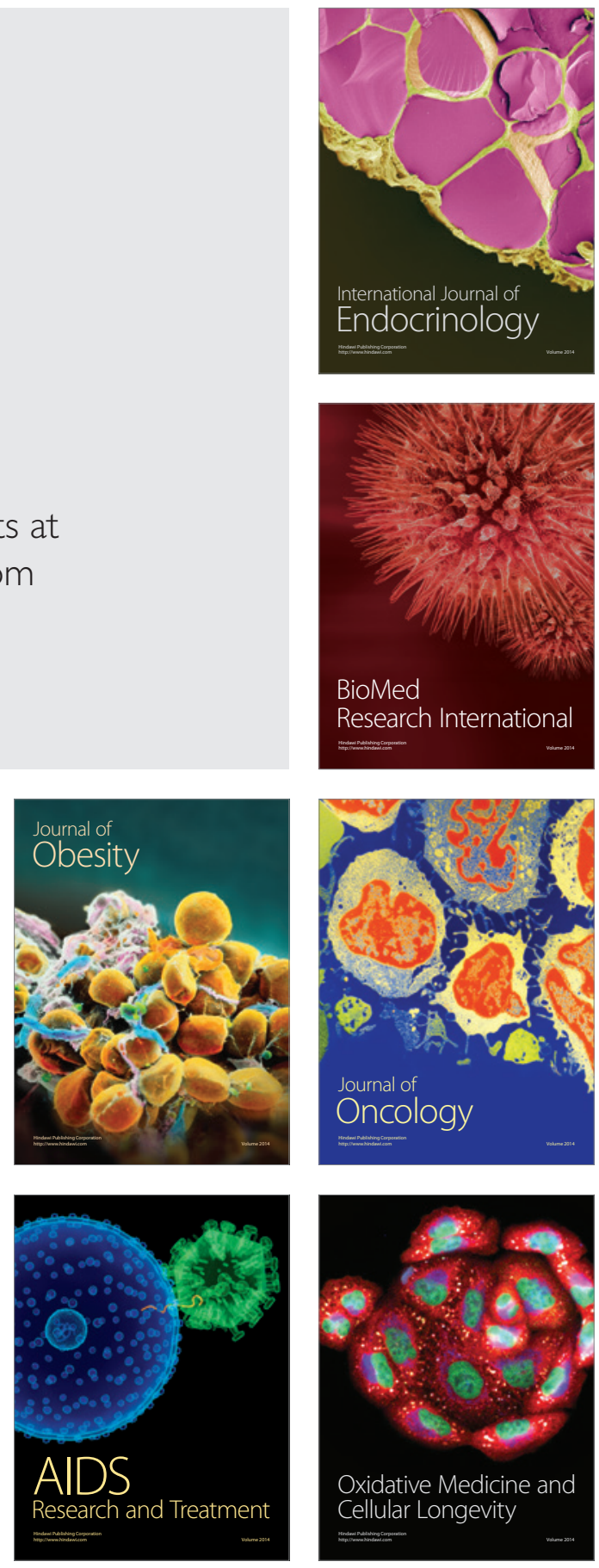